\title{
Green Oxidation of Alcohols to Carbonyl Compounds by Heterogeneous Photocatalysis
}

\author{
Vincenzo Augugliaro and Leonardo Palmisano*[a]
}

The selective conversion of alcohols to carbonyl compounds is essential for the preparation of fragrances, food additives, and many organic intermediates. ${ }^{[1]}$ This transformation is carried out by catalytic processes that are of fundamental importance in synthetic chemistry. ${ }^{[2]}$ Catalytic oxidation has long been carried out in environmentally harmful organic solvents (often chlorinated ones) at high temperatures and pressures by employing stoichiometric amounts of various inorganic oxidants, for example chromate and permanganate species, that play the role of oxygen donors. The latter oxidants are not only expensive and toxic but also produce large amounts of dangerous wastes, so that investigations have been concerned with substituting them for safer systems.

In recent years, significant progress has been made in the development of effective catalytic processes for the aerobic oxidation of alcohols ${ }^{[3]}$ with environmentally benign and inexpensive oxidants such as oxygen or air. Typically, the aerobic oxidation of alcohols involves the use of catalysts based on platinum-group metals and transition metal compounds. The latter are (1) transition metal complexes, which comprise a central metal atom and surrounding organic ligand(s); and (2) inorganic catalysts, mainly polyoxometalates ${ }^{[4,5]}$ (POMs), typically oxides of molybdenum, tungsten, and vanadium. POMs are well-defined early transition metal-oxygen clusters with unique structural characteristics and catalytic properties. ${ }^{[6,7]}$ Interestingly, many POMs share photochemical characteristics very similar to those of semiconductor photocatalysts, so that POMs represent the analogues of semiconductor metal oxides. ${ }^{[8]}$ According to thermodynamics, an alcohol molecule with singlet electronic configuration cannot directly react with an unactivated dioxygen molecule, which has a triplet electronic configuration. ${ }^{[9]}$ The working mechanism for all metal oxidation catalysts is that the metal atom mediates the electron transfer, and thereby induces the formation of singlet oxygen.

In this respect, a wide range of homogeneous metal catalysts has been found capable to use molecular oxygen as the only oxidant. ${ }^{[10-13]}$ For example, a water-soluble palladium(II) batho-phenanthroline complex has been used as catalyst at a pressure of 30 bar and a temperature of $373.16 \mathrm{~K}$ for the aero-

[a] Prof. V. Augugliaro, Prof. L. Palmisano

"Schiavello-Grillone" Photocatalysis Group

Dipartimento di Ingegneria Chimica dei Processi e dei Materiali Università di Palermo

Viale delle Scienze, 90128 Palermo (Italy)

Fax: $(+39)$ 091-7025020

E-mail:palmisano@dicpm.unipa.it bic oxidation of a wide range of alcohols to aldehydes, ketones, and carboxylic acids in a biphasic water/alcohol system. ${ }^{[14]}$ The alcohol conversion was almost complete and the yield of carbonyl compounds was in the range 79-90\%, depending on the substrate.

The use of homogeneous catalysts, however, offers obvious disadvantages over heterogeneous systems with respect to ease of handling and catalyst recycling. A wide range of supported platinum and palladium catalysts has long been reported to exhibit high catalytic performance in the oxidation of alcohols. ${ }^{[15-17]} \mathrm{Au} / \mathrm{Pd}-\mathrm{TiO}_{2}$ catalysts showing high turnover frequencies (up to 270000 turnovers per hour) have been also proposed. ${ }^{[18]}$ These catalysts, used for carrying out the oxidation of benzyl alcohol to benzaldehyde, showed an alcohol conversion of $74.5 \%$ and an aldehyde selectivity of $91.6 \%$, benzyl benzoate being the only detected byproduct.

Even if the catalytic systems have proven rather effective, from a green chemistry perspective their application is often limited by environmental risks. Consequently the search for economic and safe reactions to afford selective oxidation of alcohols using molecular oxygen but avoiding high $\mathrm{pH}$ values and the presence of metal complexes catalysts has attracted great attention. ${ }^{[1]}$ In this context the search for an oxidation catalyst capable of directly activating dioxygen is an interesting as well as challenging task.

Heterogeneous photocatalysis (HP) by polycrystalline semiconductor oxides is an unconventional technology that has been mainly applied in the field of environmental remediation to degrade organic and inorganic pollutants in air and wastewaters. ${ }^{[19,20]} \mathrm{TiO}_{2}$ is the most-often-used photocatalyst, owing to its reliability, low cost, and (photo)stability under irradiation, although different semiconductor and insulator solids have also been used as photocatalysts. Some of them, for example $\mathrm{ZnO}$, give rise to anodic photocorrosion in water and consequently they can not be used safely. In addition to decontamination, HP has been applied for carrying out many selective photocatalytic reactions in the absence of solvent or in nonaqueous solvents such as acetonitrile or water/acetonitrile mixtures.

Heteropolyoxometalate catalysts of the type $\left[\mathrm{S}_{2} \mathrm{M}_{18} \mathrm{O}_{62}\right]^{4+}$ $(\mathrm{M}=\mathrm{W}, \mathrm{Mo})^{[21]}$ have been used to carry out the photo-oxidation of aromatic alcohols under sunlight and UV/Vis light in acetonitrile. Mechanistic investigations of photocatalysis by these nontoxic compounds indicate that near-UV/Vis irradiation of a POM solution results in an O-to-M charge-transfer excited state that has strong oxidation ability and is responsible for the oxidation of organic substrates, photoexcited POMs 
being reduced by the transfer of one or two electron(s) from the organic substrate. Reoxidation (regeneration) of the photoreduced POMs to their original oxidation state can easily be affected by oxygen, and this reaction is the basis of their photocatalytic activity. Most POMs are highly soluble in polar solvents and suffer from an inability to be recycled. Therefore, water-tolerant solid POMs ${ }^{[22]}$ were prepared by combining homogeneous POMs with photoactive and inactive supporting materials (e.g., mesoporous molecular sieve, $\mathrm{NaY}$ zeolite, $\mathrm{TiO}_{2}$ in amorphous or anatase phase). Recently, progress has been made in the preparation of desolubilized POMs, creating heterogeneous photocatalysts by encapsulating the POM molecules into a silica matrix via a sol-gel process. A recent application of heterogenized POMs as photocatalysts for synthetic purposes concerns the oxidation of benzylic alcohols using sol-gel silica-encapsulated $\mathrm{H}_{3} \mathrm{PW}_{12} \mathrm{O}_{40}{ }^{[23]}$ The reaction takes place under an $\mathrm{O}_{2}$ atmosphere that acts as a stoichiometric reoxidant catalyst, thereby allowing recycling and reuse of POM. Table 1 reports some reactivity results obtained with this system.

Table 1. Photocatalytic oxidation of benzylic alcohols with $\mathrm{O}_{2}$ catalyzed by $\mathrm{H}_{3} \mathrm{PW}_{12} \mathrm{O}_{40} / \mathrm{SiO}_{2}{ }^{[23]}$ Reaction: $\operatorname{Ar}(\mathrm{COH}) \mathrm{R} \rightarrow \operatorname{Ar}(\mathrm{CO}) \mathrm{R}$.

\begin{tabular}{llll|}
$\mathrm{Ar}$ & $\mathrm{R}$ & Irradiation time [h] & Yield [\%] \\
\hline $\mathrm{C}_{6} \mathrm{H}_{5}$ & $\mathrm{H}$ & 2.5 & 75 \\
$p-\mathrm{MeC}_{6} \mathrm{H}_{4}$ & $\mathrm{H}$ & 1 & 92 \\
$o-\mathrm{MeC}_{6} \mathrm{H}_{4}$ & $\mathrm{H}$ & 1 & 90 \\
$p-\mathrm{ButC}_{6} \mathrm{H}_{4}$ & $\mathrm{H}$ & 1.5 & 82 \\
$p-\mathrm{MeOC}_{6} \mathrm{H}_{4}$ & $\mathrm{H}$ & 1.5 & 85 \\
$o-\mathrm{MeOC}_{6} \mathrm{H}_{4}$ & $\mathrm{H}$ & 2 & 70 \\
$p-\mathrm{ClC}_{6} \mathrm{H}_{4}$ & $\mathrm{H}$ & 1.5 & 80 \\
$p-\mathrm{BrC}_{6} \mathrm{H}_{4}$ & $\mathrm{H}$ & 2 & 82 \\
$\mathrm{C}_{6} \mathrm{H}_{5}$ & $\mathrm{CH}$ & 2 & 84 \\
$p-\mathrm{MeC}_{6} \mathrm{H}_{4}$ & $\mathrm{CH}$ & 1 & 97 \\
$p-\mathrm{NO}_{2} \mathrm{C}_{6} \mathrm{H}_{4}$ & $\mathrm{CH}_{3}$ & 3 & 76 \\
$\mathrm{C}_{6} \mathrm{H}_{5}$ & $\mathrm{C}_{2} \mathrm{H}_{5}$ & 1.5 & 90 \\
$\mathrm{C}_{6} \mathrm{H}_{5}$ & $\mathrm{C}_{6} \mathrm{H}_{5}$ & 2 & 84 \\
$p-\mathrm{ClC}_{6} \mathrm{H}_{4}$ & $\mathrm{C}_{6} \mathrm{H}_{5}$ & 1.5 & 88 \\
$p-\mathrm{MeOC}_{6} \mathrm{H}_{4}$ & $\mathrm{C}_{6} \mathrm{H}_{5}$ & 1.25 & 90 \\
$p-\mathrm{NO}_{2} \mathrm{C}_{6} \mathrm{H}_{4}$ & $\mathrm{C}_{6} \mathrm{H}_{5}$ & 3 & 72 \\
$\mathrm{C}_{6} \mathrm{H}_{5}$ & $\mathrm{CH}_{2} \mathrm{OH}$ & 2 & 75 \\
\hline
\end{tabular}

Selective oxidation of various primary and secondary alcohols was studied in a gas-phase photochemical reactor at $463 \mathrm{~K}$ using light-activated immobilized $\mathrm{TiO}_{2}{ }^{[24]}$ Benzylic alcohols gave higher conversions with more secondary reaction products. Photocatalytic oxidation of selected aryl alcohols in acetonitrile was carried out by using anatase $\mathrm{TiO}_{2}$ as catalyst. ${ }^{[25]}$ The main oxidation products were the corresponding aldehydes or ketones and acids, in addition to unidentified minor compounds.

Liquid 2-propanol has been photo-oxidized to propanone in the presence of semiconductor-zeolite composites, consisting of either $\mathrm{CdS}$ or $\mathrm{TiO}_{2}$ in $\mathrm{Y}$ zeolite. ${ }^{[26]}$ CdS-based composites were prepared by cation exchange with $\mathrm{Cd}^{2+}$ followed by sulfidation with either $\mathrm{Na}_{2} \mathrm{~S}$ or $\mathrm{H}_{2} \mathrm{~S}$, whereas $\mathrm{TiO}_{2}$-based composite was prepared by $\mathrm{Ti}(\mathrm{OEt})_{4}$ impregnation followed by hydrolysis and calcination. Rate measurements under standard conditions over the temperature range $283-308 \mathrm{~K}$ yielded the same activation energies as for $\mathrm{CdS}$ and $\mathrm{TiO}_{2}$ supported on $\mathrm{Al}_{2} \mathrm{O}_{3}$.

While HP in the presence of water has been applied to the complete mineralization of many different species, applications of HP for synthetic purposes in water have been developed only recently. The reason of this "delay" lies in the mechanism invoked for explaining photocatalytic reactions: the presence of water, both as vapor and liquid phase, induces the photoproduction of strong oxidant species $(\mathrm{OH}$ radicals) on the catalyst surface, and then the fast and indiscriminate attack of those radicals to the species adsorbed on the catalyst surface. Photocatalytic reactions have been considered unselective processes on the basis of this mechanism.

The first remarkable selective aerobic photocatalytic oxidation of alcohol to aldehyde in water at room temperature concerned the oxidation of 4-methoxybenzyl alcohol (MBA) to 4methoxybenzaldehyde ( $p$-anisaldehyde), a compound used in sweet blossom and flavor compositions and as an intermediate in many industrial processes. The oxidation was performed in aqueous suspensions of nanostructured home-prepared titanium dioxide (HPTD) samples (anatase or anatase/rutile mixtures). ${ }^{[27]}$ The photocatalysts were prepared by hydrolysis of $\mathrm{TiCl}_{4}$ and the selectivity of the sample depended on the duration of boiling $(0.5,2,4$, and $6 \mathrm{~h})$. The most selective one was the anatase sample obtained after $0.5 \mathrm{~h}$ boiling, which gave rise to ca. $42 \% \mathrm{~mol}$ selectivity determined for ca. $65 \% \mathrm{~mol}$ conversion of the starting alcohol. Commercial samples (Merck anatase and Degussa P25) showed lower selectivities (ca. 14 and $10 \%$, respectively) in similar experimental conditions, although the reaction rate was significantly higher. In Table 2 some results obtained with various samples in different experimental conditions are reported.

Home-prepared rutile (HPR) $\mathrm{TiO}_{2}$ catalysts were prepared at room temperature and used in aqueous suspension, free from

\begin{tabular}{|c|c|c|c|c|}
\hline Photocatalyst & $\begin{array}{l}\text { Catalyst amount } \\
{\left[\mathrm{g} \mathrm{L}^{-1}\right]}\end{array}$ & $\begin{array}{l}\text { Irradiation } \\
\text { time }[\mathrm{h}]\end{array}$ & $\begin{array}{l}\text { Yield } \\
\text { [mol\%] }\end{array}$ & $\begin{array}{l}r_{0} 10^{12} \\
{\left[\mathrm{mols}^{-1} \mathrm{~m}^{-2}\right]}\end{array}$ \\
\hline $\operatorname{Merck}(\mathrm{A})$ & 0.02 & 13.8 & 13.6 & 122 \\
\hline Merck (A) & 0.1 & 6.5 & 12.3 & 48.7 \\
\hline $\operatorname{Merck}(A)$ & 0.2 & 5.2 & 12.0 & 30.8 \\
\hline Merck (A) & 0.4 & 3.9 & 9.5 & 19.7 \\
\hline $\operatorname{Merck}(A)$ & 0.4 & 3.7 & 11.7 & 23.3 \\
\hline Merck (A) & 0.4 & 4.2 & 9.0 & 14.7 \\
\hline Merck (A) & 0.8 & 3.0 & 10.2 & 25.5 \\
\hline Merck (A) & 2 & 1.8 & 10.0 & 32.2 \\
\hline P25 $(A, R)$ & 0.02 & 5.6 & 10.8 & 53.0 \\
\hline P25 (A,R) & 0.1 & 1.9 & 10.0 & 164 \\
\hline P25 $(A, R)$ & 0.2 & 0.9 & 8.7 & 257 \\
\hline HPTD0.5 (A) & 0.02 & 15.5 & 30.4 & 7.78 \\
\hline HPTD0.5 (A) & 0.1 & 9.6 & 38.5 & 3.04 \\
\hline HPTD0.5 (A) & 0.2 & 7.7 & 41.5 & 1.75 \\
\hline HPTD0.5 (A) & 0.3 & 6.0 & 31.9 & 1.42 \\
\hline HPTD2 (A) & 0.2 & 4.7 & 36.7 & 1.75 \\
\hline HPTD4 $(A, R)$ & 0.2 & 3.9 & 35.6 & 2.61 \\
\hline HPTD6 $(A, R)$ & 0.2 & 2.8 & 31.1 & 4.03 \\
\hline HPTD8 (R,A) & 0.2 & 3.2 & 32.5 & 4.11 \\
\hline
\end{tabular}


any organic co-solvent, for carrying out the MBA partial oxidation. The selectivities showed by the HPR catalysts for the MBA partial oxidation were higher than those of anatase (ca. $60 \%$ mol versus $42 \% \mathrm{~mol}$, in the best experimental conditions). ${ }^{[28,29]}$ By using the most selective HPR photocatalyst, the selective photocatalytic oxidation of benzyl alcohol (BA), 4-methylbenzyl alcohol (MeBA), and 4-nitrobenzyl alcohol (NBA) to the corresponding benzaldehydes was also carried out in order to investigate the influence of the substituent group on the partial oxidation rate and selectivity. ${ }^{[30]}$ The results are reported in Table 3, together with those obtained with a commercial rutile

\begin{tabular}{|c|c|c|c|c|}
\hline Substrate & Catalyst & $\begin{array}{l}t_{1 / 2}^{[a]} \\
{[\mathrm{h}]}\end{array}$ & $\begin{array}{l}\text { Selectivity } \\
{[\%]}\end{array}$ & $\begin{array}{l}k 10^{2[b]} \\
{\left[h^{-1}\right]}\end{array}$ \\
\hline \multirow[t]{2}{*}{ MBA } & HPR & 2.6 & 72 & 19.2 \\
\hline & SA & 2.15 & 21 & 5.6 \\
\hline \multirow[t]{2}{*}{ MeBA } & HPR & 4.2 & 47 & 7.8 \\
\hline & SA & 4.2 & 9.5 & 2.5 \\
\hline \multirow[t]{2}{*}{ BA } & HPR & 6.5 & 42 & 4.5 \\
\hline & SA & 3.8 & 9.2 & 1.7 \\
\hline \multirow[t]{2}{*}{ NBA } & HPR & 9.8 & 5.3 & 0.37 \\
\hline & SA & 6.7 & 3.3 & 0.24 \\
\hline
\end{tabular}

[a] Reaction time needed for $50 \%$ alcohol conversion. [b] First-order kinetic constant of the partial oxidation reaction of the substituted reactant.

$\mathrm{TiO}_{2}$ sample (Sigma Aldrich, SA). In reference to the oxidation rate, the reaction times needed to achieve $50 \%$ conversion of alcohol decreased in the order $B A>M e B A>M B A$, while time was longer from $B A$ to NBA. This order indicates that the electronic properties of the substituent groups play a very significant role on the reaction rate, which is enhanced by electrondonating substituents and retarded by electron-withdrawing substituents. The influence of the substituent group on the rate of partial oxidation of aromatic alcohols is well described by the Hammett relationship, the validity of which is widely confirmed for homogeneous reaction systems but in only very few cases in heterogeneous photocatalytic systems. Finally, brookite $\mathrm{TiO}_{2}$ was separated by peptization from the brookiterutile suspension and tested for 4-methoxybenzyl alcohol photo-oxidation to 4-methoxybenzaldehyde, showing a selectivity similar to that of the anatase phase. ${ }^{[31]}$

A common characteristic of all of the above prepared $\mathrm{TiO}_{2}$ samples is their low crystallinity, as revealed by X-ray diffraction analysis, and the small size (ca. $5-10 \mathrm{~nm}$ ) of their primary particles. A not-complete knowledge of the detailed photocatalytic mechanism for selective oxidation of organics and the slow reaction rates relative to those of the systems based on noble or transition metals are drawbacks for an immediate large-scale application of the photocatalytic process. A recently reported result ${ }^{[32]}$ reported an unexpected transfer of an oxygen atom from molecular oxygen into alcohols as the key step during the photocatalytic transformation of alcohols into the corresponding carbonyl compounds (see Figure 1). The oxygen isotopic labeling study presented indicates different characteristics of the $\mathrm{TiO}_{2}$ photocatalytic mechanism compared to catalysis by noble or transition metal complexes. ${ }^{[33,34]}$

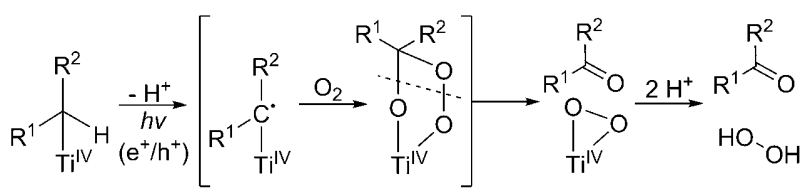

Figure 1. Proposed mechanism of the photocatalytic partial oxidation of alcohols. ${ }^{[32]}$

Stuchinskaya et al. studied the aerobic oxidation of alcohols to aldehydes and ketones on Ru-Co oxide catalyst, ${ }^{[35]}$ and they concluded that this reaction system can be viewed as an oxidative dehydrogenation that does not affect the oxygen atom of an alcoholic group, whereas the formation of acids is an oxygenation; that is, it involves oxygen atom incorporation. Concerning the mechanism, the Ru-catalyzed oxidative dehydrogenation of alcohols is likely to occur via the formation of $\mathrm{Ru}^{\mathrm{IV}}$ alkoxide followed by $\beta$-elimination of Ru hydride species to yield the aldehyde or ketone, and subsequently catalyst regeneration by $\mathrm{O}_{2}$ (Figure 2).

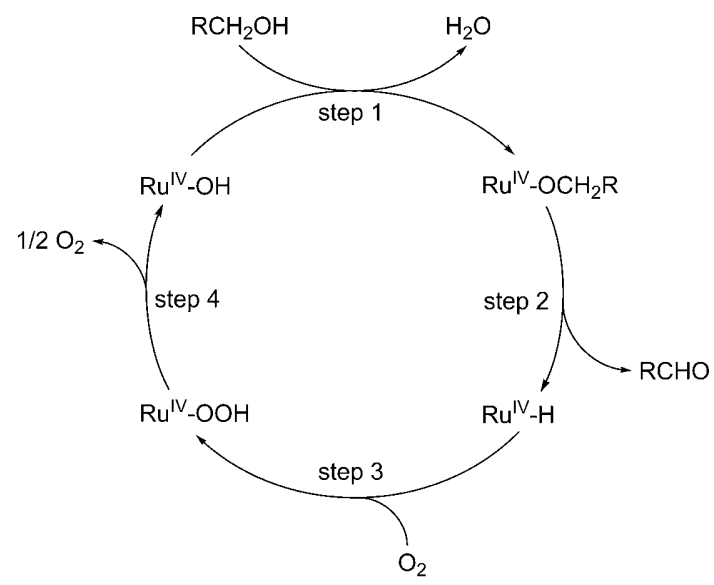

Figure 2. Mechanism of alcohol oxidation catalyzed by $\mathrm{Ru}^{\mathrm{IV}}$.[35]

Moreover, another recent paper describes the acceleration of the aerobic photo-oxidation of alcohols on $\mathrm{TiO}_{2}$ or $\mathrm{SiO}_{2} / \mathrm{TiO}_{2}$ samples without any loss of selectivity via surface loading of Brønsted acids (reaction time 2-7 h, conversion of the starting molecules ca. $42-100 \%$ mol, selectivity $73-100 \% \mathrm{~mol}){ }^{[36]}$ The effect of Brønsted acids was confirmed and enhanced when a small quantity of $\mathrm{SiO}_{2}$ was incorporated into $\mathrm{TiO}_{2}$ after the acid pretreatment, due to the presence of more acid sites on the $\mathrm{TiO}_{2}$ surface. 
The acceleration effect was attributed to the protons of Brønsted acids that effectively promote the decomposition of the formed surface peroxide-Ti species. This was demonstrated by means of in situ spectroscopy titrations. These indicated that this phenomenon leads to the regeneration of the surface sites contributing to an enhancement of the cycle efficiency without any loss of selectivity. The findings reported by Wang et al. strengthen the studies reported in Refs. [27-31] as a new path to obtain both high selectivity and acceptable reaction rates.

\section{Acknowledgements}

The authors acknowledge the fundamental contributions of $M$. Bellardita, A. Di Paola, E. García-López, V. Loddo, G. Marcì, G. Palmisano, and S. Yurdakal to the activity of the "Schiavello-Grillone" Photocatalysis group.

Keywords: alcohols • chemoselectivity - heterogeneous catalysis $\cdot$ oxidation $\cdot$ photocatalysis

[1] T. Mallat, A. Baiker, Chem. Rev. 2004, 104, 3037-3058.

[2] C. N. Satterfield, Heterogenous Catalysis in Industrial Practice, McGrawHill, New York 1991.

[3] G. W. Parshall, S. D. Ittel, Homogeneous Catalysis, Wiley, New York 1992.

[4] R. H. Holm, Coord. Chem. Rev. 1990, 100, 183-221.

[5] I. A. Weinstock, Chem. Rev. 1998, 98, 113-170.

[6] T. Okuhara, Appl. Catal. A: Gen. 2003, 256, 213-224.

[7] I. V. Kozhevnikov, Chem. Rev. 1998, 98, 171-198.

[8] A. Hiskia, A. Mylonas, E. Papaconstantinou, Chem. Soc. Rev. 2001, 30, 62-69.

[9] R. Ho, J. Liebman, J. Valentine, in Active Oxygen in Chemistry (Eds.: C. Foote, J. Valentine, A. Greenberg, J. Liebman), Springer, Berlin 1995, pp. $1-23$.

[10] P. T. Anastas, J. C. Warner, Green Chemistry: Theory and Practice, Oxford University Press, New York 2000.

[11] I. C. W. E. Arends, R. A. Sheldon, in Modern Oxidation Methods (Ed.: J.-E. Bäckvall), Wiley-VCH, Weinheim, 2004, pp. 83-118.

[12] I. László, Simandi, Advances in Catalytic Activation of Dioxygen by Metal Complexes, Kluwer Academic, Dordrecht 2004.

[13] S. S. Stahl, Angew. Chem. 2004, 116, 3480-3501; Angew. Chem. Int. Ed. 2004, 43, 3400-3420.
[14] G. ten Brink, I. W. C. E. Arends, R. A. Sheldon, Science 2000, 287, 1636 1639.

[15] T. Mallat, Z. Bodnar, P. Hug, A. Baiker, J. Catal. 1995, 153, 131-143.

[16] K. Mori, T. Hara, T. Mizugaki, K. Ebitani, K. Kaneda, J. Am. Chem. Soc. 2004, 126, 10657-10666.

[17] B.-Z. Zhan, A. Thomson, Tetrahedron 2004, 60, 2917-2935.

[18] D. I. Enache, J. K. Edwards, P. Landon, B. Solsona-Espriu, A. F. Carley, A. A. Herzing, M. Watanabe, C. J. Kiely, D. W. Knight, G. J. Hutchings, Science 2006, 311, 362-365.

[19] Advances in Chemical Engineering, Photocatalytic Technologies, Vol. 36 (Eds.: H. I. De Lasa, B. S. Rosales), Academic, New York 2009

[20] Environmentally Benign Photocatalysts, Applications of Titanium Oxide based Materials, Series: Nanostructure Science and Technology (Eds.: M. Anpo, P. V. Kamat), Springer, New York 2010.

[21] T. Rüther, A. M. Bond, W. R. Jackson, Green Chem. 2003, 5, 364-366.

[22] Y. Guo, C. Hu, J. Mol. Catal. A: Chem. 2007, 262, 136-148.

[23] S. Farhadi, M. Afshari, M. Maleki, Z. Babazadeh, Tetrahedron Lett. 2005, 46, 8483-8486.

[24] U. R. Pillai, E. Sahle-Demessie, J. Catal. 2002, 211, 434-444.

[25] O. S. Mohamed, A. E. M. Gaber, A. A. Abdel-Wahab, J. Photochem. Photobiol. A 2002, 148, 205-210.

[26] K. J. Green, R. Rudham, J. Chem. Soc. Faraday Trans. 1993, 89, $1867-$ 1870.

[27] G. Palmisano, S. Yurdakal, V. Augugliaro, V. Loddo, L. Palmisano, Adv. Synth. Catal. 2007, 349, 964-970.

[28] S. Yurdakal, G. Palmisano, V. Loddo, V. Augugliaro, L. Palmisano, J. Am. Chem. Soc. 2008, 130, 1568-1569.

[29] V. Augugliaro, T. Caronna, V. Loddo, G. Marcì, G. Palmisano, L. Palmisano, S. Yurdakal, Chem. Eur. J. 2008, 14, 4640-4646.

[30] S. Yurdakal, G. Palmisano, V. Loddo, O. Alagöz, V. Augugliaro, L. Palmisano, Green Chem. 2009, 11, 510-516.

[31] V. Augugliaro, V. Loddo, M. J. López-Muñoz, C. Márquez-Álvarez, G. Palmisano, L. Palmisano, S. Yurdakal, Photochem. Photobiol. Sci. 2009, 8 , 663-669.

[32] M. Zhang, Q. Wang, C. Chen, L. Zang, W. Ma, J. Zhao, Angew. Chem. 2009, 121, 6197-6200; Angew. Chem. Int. Ed. 2009, 48, 6081-6084.

[33] J. T. Groves, R. Quinn, J. Am. Chem. Soc. 1985, 107, 5790-5792.

[34] H. Arzoumanian, Coord. Chem. Rev. 1998, 178-180, 191-202.

[35] T. L. Stuchinskaya, M. Musawir, E. F. Kozhevnikova, I. V. Kozhevnikov, J. Catal. 2005, 231, 41-47.

[36] Q. Wang, M. Zhang, C. Chen, W. Ma, J. Zhao, Angew. Chem. Int. Ed. 2010, DOI: 10.1002/anie.201001533.

Received: June 2, 2010

Published online on September 9, 2010 